\title{
Posthumous Reproduction and Its Legal Perspective
}

\author{
${ }^{1}$ Usha Ahluwalia, ${ }^{2}$ Mala Arora \\ ${ }^{1}$ Consultant, Department of Obstetrics and Gynecology, Dewsbury and District Hospital, Mid Yorkshire Hospitals \\ NHS Trust, Dewsbury, West Yorkshire \\ ${ }^{2}$ Consultant Infertility and IVF, Noble Hospital and IVF Center, Faridabad, Haryana, India
}

Correspondence: Mala Arora, Consultant Infertility and IVF, Noble Hospital and IVF Center, Faridabad-121007, Haryana, India e-mail: narindermala@gmail.com

\section{ABSTRACT}

Assisted reproductive techniques allow us to use donated and cryopreserved gametes posthumously. This can pose legal issues, such as legitimacy of the child born, inheritance rights of the child, and life long psychosocial implications. The law in different countries takes a varied stand on it. Posthumous use of gametes must abide by the law of the land. A valid consent of the deceased is required. Mourning period of at least one year should be allowed prior to embarking on ART procedures on the surviving partner. The law regarding legitimacy of the child born after death or divorce of a spouse needs amendment. The psychological development of these children needs to be studied by long-term studies.

Keywords: Posthumous reproduction, ART, Legal perspective.

\section{INTRODUCTION}

Medically assisted reproduction sometimes involve treating infertile couples using their own or donated genetic material, whether sperms, eggs or even embryos, posthumously. Here comes the need for government guidelines and laws to ensure that these technologies are used safely and responsibly. The UK government had set up a Committee of Inquiry (Warnock Committee) into Human Fertilisation and Embryology chaired by Baroness Warnock, which reported in 1984. It identified the range of concerns, which arose from the rapid developments in the field of medically assisted reproduction and recommended updates in legislation.

The first legislation in the world to regulate assisted reproduction was the Infertility Act 1984 in Victoria, Australia-since replaced by the Infertility Treatment Act 1995(Vic). Subsequently a number of jurisdictions have legislated, including South Africa (Reproductive Technology Act 1988) and Western Australia (Human Reproductive Technology Act 1991). In the UK, the regulation was through the Human Fertilisation and Embryology Act 1990. The regulatory framework took effect on 1 August 1991 and apart from Surrogacy (regulated by Surrogacy Arrangements Act 1985), seeks to establish a comprehensive legislative framework. In Europe, legislation also exists in a number of countries, e.g. France, Holland, Germany, Austria, Norway, Sweden, Denmark, and Spain.

Date of Received: 06-12-10

Date of Acceptance: 03-01-11

Date of Publication: Jan. 2011

\section{POSTHUMOUS USE OF GAMETES AND EMBRYO}

English law gives prominence to the procreative liberty of the gamete-providers, even following the death of one of them. The 1990 Act permits posthumous use of sperms or embryos by a widow, provided her husband or partner has given written consent prior to his death.

Some jurisdictions take a different view making it a criminal offence to use gametes or embryos of the dead, e.g. s.43 Infertility Treatment Act 1995 (Vic).

\section{Infertility Treatment Act 1995: Section 43 (Australia)}

Section 43 bans on procedures involving gametes of people known to be dead.

A person must not:

- Inseminate a woman with sperm from a man known to be dead; or

- Transfer to a woman a gamete from a person known to be dead.

- Transfer to a woman a zygote or an embryo formed from a gamete from a person known to be dead; or

- Form a zygote with sperm from a man known to be dead; or

- Form a zygote, if the woman who produced the oocyte used to form the zygote is known to be dead.

Penalty: 240 penalty units or 2 years imprisonment or both.

Courts have already been called upon to resolve disputes over the status of parents and children when medical technology is used to conceive a child after the death of a parent, and it is certain that in the coming years such cases will become even more common. 
Specifically, the development of cryopreservation (the technology of freezing used to preserve individual gametes and embryos) has created the potential for noncoital posthumous conception of children. ${ }^{1}$ The creation of babies by assisted and collaborative techniques of reproduction, such as invitro fertilization or cryopreservation of gametes and embryos, stimulates strong emotions and fantasies about life, death, sexuality and immortality. Particularly, the cryopreservation of spermatozoa for postmortem reproduction forces us to come to terms with the meaning of human reproduction, and the extent of individual rights to procreate using artificial means. ${ }^{2}$

Postmortem sperm retrieval was first reported in 1980 by Rothman, in a case involving a 30-year-old man who became brain dead following a motor vehicle accident and whose family requested sperm preservation (Rothman, 1980). ${ }^{3}$ Ohl et al reported family requests for sperm retrieval in one case involving a patient in the persistent vegetative state (PVS), one case in which the patient was in an extended coma with a poor prognosis for recovery, and four cases involving brain dead patients (Ohl et al 1996). ${ }^{4}$ Several other case reports involving postmortem sperm retrieval have been published (Nolan et al 1990; ${ }^{5}$ Pozda 1996; ${ }^{6}$ Townsend et al $1996 ;{ }^{7}$ Iserson 1998). ${ }^{8}$

\section{Techniques of Sperm Retrieval}

Various methods for retrieving spermatozoa have been described, including surgical excision of the epididymis, ${ }^{6}$ irrigation or aspiration of the vas deferens, ${ }^{9}$ and rectal probe electroejaculation. ${ }^{7}$ A survey of fertility centers in the $\mathrm{USA}^{9}$ found that a total of 40 centers reported 82 requests for postmortem sperm retrieval between 1980 and July 1995. Pregnancy following postmortem sperm retrieval was reported for the first time in 1998, ${ }^{10}$ and a subsequent birth was reported in March 1999. ${ }^{11}$ Media coverage is raising public awareness of such sperm retrieval, and more frequent family requests for it following death or PVS seem likely in the future. Regardless of the method used, the retrieval should be performed within 24 to 36 hours of death. Intense screening for infectious diseases like HIV and hepatitis B, similar to those used for donor insemination, should be applied for the safety of the mother and fetus.

It is increasingly common for men, for example, to store sperm for potential use by wife or girlfriend in the event of their deaths. Soldiers who are assigned to combat zones, men who have cancer or other terminal illnesses, or athletes and others engaged in dangerous activities might also elect to have their sperm cyropreserved. ${ }^{12}$ Sperm harvesting, the process by which sperm is extracted following a man's death, is a source of cryopreserved gametes for postmortem conception that has received public recognition. ${ }^{13}$ In addition, advances in longterm preservation of female ova (eggs) might enable a child to be born after the death of its genetic mother. ${ }^{14}$ Surplus cryopreserved embryos resulting from in vitro fertilization treatments during the lives of the gamete providers ${ }^{15}$ could also be designated in a will or other legal document for potential use for postmortem conception of children, following the death of the gamete providers. The availability of these gametes and embryos after death creates ample resources for the posthumous conception of children.

\section{LEGAL ISSUES}

Until very recently, legal issues surrounding posthumous children focused on inheritance rights of a child who was conceived while the biological parents were alive with the child being born after the death of the father. The law largely deals with this problem by providing for the legal heirship of children born within the normal gestational period following the death of the father. But the development of technologies such as intrauterine insemination, in vitro fertilization, surrogacy, cryopreservation of gametes and embryos have created the potential for an entirely different set of legal issues.

These issues are not based on the birth of a child after the death of the father when the child is conceived prior to the father's death. Instead, they are based on conceiving a child or implanting a pre-existing embryo after the death of a genetic parent or parents. Children, who are conceived during the lives of their parents, even if born after the death of a parent, are protected under the laws of inheritance and are considered lawful heirs.

Inheritance issues involving the status of children, who are conceived posthumously by use of assisted reproduction, however, are more legally ambiguous. Posthumous children of assisted reproduction who are born long after the death of a parent may fall outside the purview of statutes originally designed to protect naturally conceived but posthumously born children.

Certainly the law should seek to protect posthumous children conceived after the death of one or both of their parents, but their inheritance rights may depend on a wide range of considerations, including legislative willingness to address such novel and often controversial issues. Persons involved in posthumous reproduction should legally establish or disestablish familial relationships since inheritance rights historically have had their origin in legally recognized familial relationships.

In the US, the states which have statutes protecting sperm donors from liability, if a posthumous child discovers the identity of his genetic father/sperm donor, he or she would have no claim of inheritance from the donor's estate. ${ }^{16}$ However, even the estates of anonymous donors may be vulnerable if the state has no statute clearly giving the donor's estate immunity from claims by the posthumous child. When a donor's identity is revealed, his estate may be subject to potential liability in the absence of statutory protection.

A child could also be the posthumous product of a deceased egg donor. Some state statutes only reference sperm donors and intrauterine insemination, leaving the estates of egg donors in those states potentially vulnerable to claims. The potential rights and responsibilities of egg donors are not expressly legally protected in most states, and any child who is conceived posthumously from the egg of a deceased egg donor could 
conceivably discover that donor's identity and make a claim to her estate. ${ }^{17}$

A child could also be the posthumous product of a cryopreserved embryo, created by two deceased gamete providers. Potentially, such a child could make a claim against both genetic mother and father's estates.

The success of such claims would, in large part, depend on the child's status as related to the gamete providers. Relevant areas of inquiry include whether the;

- Child already has two legal parents

- Gamete provider(s) provided for or excluded posthumous children in their estate planning

- Gametes provider(s) consented to the postmortem use of their gametes or embryos

- Gamete provider's estate was already administered when the claim of the posthumous child was made

- Governing state has statutory law governing the inheritance rights of the posthumously conceived; and

- Governing state has laws insulating gamete and/or embryo donors from such claims.

The general rule in the United States is that a child born after the death of a parent is not an heir under the law of inheritance, unless that child was conceived naturally (i.e. by sexual intercourse). ${ }^{18}$ For this reason, some states would probably deny posthumously conceived children of assisted reproduction inheritance rights in the estate of a deceased parent unless the child was born to a surviving spouse within a specific number of days after death as provided in an afterborn child statute. ${ }^{19}$ The most recent version of the Uniform Parentage Act (UPA) 2000, revised in 2002, contains a provision specifically addressing posthumous parentage in the context of assisted reproduction. The UPA provides "if an individual who consented in a record to be a parent by assisted reproduction dies before placement of eggs, sperm or embryos, the deceased individual is not a parent of the resulting child unless the deceased individual consented in a record that if assisted reproduction were to occur after death, the deceased individual would be a parent of the child”. ${ }^{20}$

\section{Consent}

The most important factor in relation to children of assisted reproduction is that the deceased gamete provider must have consented in writing and such consent to posthumous conception must be clearly established by other evidences. In the absence of that consent, most posthumously conceived children would probably be denied the right to inherit from the deceased.

A man's explicit prior or reasonably inferred consent is necessary for the ethical justification of sperm retrieval following death or PVS. This implies that written consent or verbal consent documented by a health care provider is not an absolute requirement, although such documentation would be desirable.

Another set of issues involves the terms of the sperm storage and insemination agreement. These issues arise regardless of whether explicit prior consent to sperm retrieval and storage is a legal requirement or reasonably inferred consent is legally acceptable. Included among these issues are:

- Whether there should be restrictions on who can be inseminated with the spermatozoa; and

- Whether there should be limits on the length of time for storage of spermatozoa retrieved after death.

However, the storage agreement should specify the disposition of the spermatozoa in the event of the incapacity of the authorized decision maker.

The consent issue gets interesting in cases where sperm is extracted right after a person's death (a process known as sperm harvesting). ${ }^{21}$ What if the couple had talked about having a child, death was unexpected, and the wife still wanted to fulfill her dreams of having genetic children with her late husband? What will suffice as "consent" of the deceased? In such a scenario, the reproductive rights of both, the deceased and the surviving spouse, are at issue. Without a doubt, more litigation will be spawned in this area, as more and more rights are implicated by the possibility of posthumous reproduction, especially those of pre-existing family members, such as older siblings.

Some potential problems can be avoided by creating thorough estate planning documents, clearly outlining the intent of the parties. Some clients may be resistant to highlighting unusual conception scenarios in their estate documents, especially if the children conceived through assisted reproduction are unaware of how they came into being. Nevertheless, it is important for attorneys to advise their clients of the potential complications in failing to address the circumstances of their children's births in their estate plan. In absence of an estate plan, a court will solve disputes by applying applicable State law, which may or may not result in the deceased's wishes being honored or in any resulting child's interests being protected.

\section{GOVERNMENTAL POLICIES}

Different governments have responded to posthumous reproduction in different ways. Germany, Sweden, Canada, and the state of Victoria, Australia have legislation that prohibits posthumous assisted reproduction (Bahadur, 1996; ${ }^{22}$ Webb, 1996). ${ }^{23}$ Western Australia has regulations that forbid posthumous use of gametes (Webb, 1996). With regard to preembryos, Israel allows their transfer to the wife within one year of a husband's death, even in the absence of his consent. However, if the wife dies, the pre-embryos cannot be used (Benshushan and Schenker, 1998). ${ }^{24}$ In regard to spermatozoa, in the UK, the 1990 Human Fertilisation and Embryology Act does not prohibit posthumous storage and use of spermatozoa, but it requires the man's prior written consent for sperm storage. Thus, postmortem retrieval, storage, and insemination would be permitted with valid written consent.

In France, after the Parpalaix case (vide infra), the Center d'Etude et de Conservation du Sperme Humain (CECOS) adopted an explicit policy of not permitting postmortem insemination, and this policy was upheld by the French courts 
(Aziza-Shuster, 1994). ${ }^{25}$ In 1994, France passed a law forbidding posthumous insemination (Lansac, 1996). ${ }^{26}$ Belgium and the USA currently permit postmortem insemination without the man's prior written consent (Brahams, 1996, ${ }^{27}$ 1997). ${ }^{28}$

Under Dutch regulation also posthumous reproduction is possible. The main rule is that if the sperm donor or one of the persons involved in the frozen embryos has died, the sperm or, as the case may be, the embryo will no longer be kept. However, if during the lifetime of the person concerned, a written declaration has been made concerning the use of the sperm or embryo in question, then that sperm or embryo may be kept (Article 7 Embryos Bill).

In Australia (The Rios Case 1984), a famous 1983 case, Mario and Elsa Rios died in an airplane crash, leaving behind two frozen pre-embryos in an IVF clinic in Melbourne, Australia, there was a great deal of debate over whether the pre-embryos should be made available to another infertile couple (Smith, 1985-86). ${ }^{29}$ The question arose whether a frozen embryo, whereby both providers of the gametes had died, had succession rights.

Under Dutch law there would be no succession rights, the legal fiction occurring under Article 1:2 of the Dutch Civil Code only being applicable if the woman were pregnant.

The ICMR guidelines in Indian states that-

Section 3.16.5, posthumous AIH through a sperm bank

Though the Indian Evidence Act 1872, says that a child born within 280 days after dissolution of marriage (by death or divorce) is a legitimate child since that is considered to be the gestation period, it is pertinent to note that this Act was enacted as far back as 1872 when one could not even visualize ART. The law needs to take note of the scientific advancements since that time. Thus, a child born to a woman artificially inseminated with the stored sperms of her deceased husband must be considered to be a legitimate child notwithstanding the existing law of presumptions under Evidence Act. The law needs to move along with medical advancements and suitably amended so that it does not give rise to dilemma or unwarranted harsh situations. ${ }^{30}$

Canada, France, Germany and Sweden have legislation that forbids posthumous reproduction. In Great Britain, the Human Fertilisation and Embryology Act of 1990 insists that those providing IVF must take into account the welfare of the child, including the need of that child for a father. It prohibits the use of aborted fetuses as egg donors for infertility treatment.

Posthumous reproduction lacks the very values that most people find in the reproductive experience, such as giving birth and rearing children. It perpetuates the myth of the 'primacy of spermatozoa' that subverts the very notions of fairness and equality in reproduction. It serves neither womens' interests nor the interests of the children they bear. Posthumous children are likely to be psychologically harmed by the idea that they have been conceived as orphans, and will never have the slightest hope of knowing their genetic fathers or learning more about their genetic mothers other than that they died before conception.

\section{ETHICAL DILEMMAS}

\section{Obligations of Physicians to Carry Out such Requests}

When family members agree that the man would want sperm retrieval, based on previous conversations with him about this matter, does the physician have a duty to carry out their request? Based on considerations of physician autonomy, a physician is free to choose not to enter into a doctor-patient relationship, except for situations in which the patient has no other access to medically necessary care that the physician in question is competent to provide. Sperm retrieval following death or PVS is not a medically necessary procedure. Thus, although the sperm retrieval is ethically justifiable in some cases, a physician who is asked to retrieve spermatozoa has no duty to agree to do it. Moreover, the principle of conscientious objection would be applicable; a physician who conscientiously opposes such sperm retrieval is free to decline to perform it. ${ }^{31}$

Each time posthumous reproduction is undertaken, there are five stakeholders; the deceased, the requesting party, the resultant child, the physician and the society. All stakeholders have a responsibility towards the resultant child.

Since this technique is new, its consequences on the resultant child are largely unknown and we require follow-up studies regarding the health and psychological welfare of such children. ${ }^{32}$

The ESHRE task force on Ethics and Law of Posthumous Assisted Reproduction ${ }^{33}$ has made the following recommendations:

- Written consent should have been given by the deceased person before the use of the gametes or embryos. Consent should be obtained at the time of storage or before the start of the IVF cycle.

- Thorough counseling of the surviving partner during the decision-making period is necessary.

- A minimum waiting period of one year after the death should be imposed before treatment can be started.

Even when consent is available, professionals have the moral obligation to consider the welfare of the resultant child. Such decisions are difficult to define and far from clear at the present moment. $^{34}$

\section{CASES}

A number of disputes have arisen in recent years over the status of nontransferred embryos cryopreserved during in vitro fertilization.

\section{USA}

\section{Hecht v. Superior Court, 1993}

Attorney William Everett Kane of Malibu, California, USA committed suicide at the age of 48 years in a Las Vegas hotel. He felt 'tired and betrayed' in business. For the past 5 years, Kane had been living with Deborah Ellen Hecht, who was 38 years old when he died. He had two college-aged children, William and Catharine, from his former wife whom he had 
divorced in 1976. On September 24, 1991, 1 month prior to his death, Kane deposited 15 vials of his spermatozoa at a California Cryobank in Los Angeles with this instruction:

I, William Everett Kane, authorize the 'sperm bank' to release my semen specimens (vials) to Deborah Ellen Hecht. I am also authorizing my specimens to be released to recipient's physician Dr Kathryn Moyer (Hecht v. Superior Court, 1993, p. 3).

His will stated:

I bequeath all right, title, and interest that I may have in any specimens of my sperm stored with any sperm bank or similar facility to Deborah Ellen Hecht.

Finally, in an unusual letter to any resulting posthumous offspring, Kane wrote:

I loved you in my dreams, even though I never got to see you born. And I wanted to leave you with something more than a dead enigma that was your father (Hecht v. Superior Court, 1993, p. 4).

Branding the desire to father a child after death 'egotistic and irresponsible,' Kane's children requested the destruction of all cryogenically preserved spermatozoa. A trial court granted the request, and on January 4, 1993, ordered the spermatozoa to be destroyed, allowing a 'stay of execution' for 60 days. Deborah Hecht appealed. Relying on Davis, the appeals court decided that spermatozoa, like embryos, are 'gametic material', and a 'unique type of property' so the gamete source should decide their use.

\section{France}

\section{Parpalaix c. CECOS, 1984}

Alain Parpalaix stored his spermatozoa at the Centre d'Etude et de Conservation du Sperme Humain (CECOS) before undertaking treatment for his testicular cancer and to safeguard his fertility. After his death, his wife Corinne requested the spermatozoa for insemination. The director of CECOS denied the request. She argued that the contract with CECOS was in the nature of a bailment, and thus 'CECOS must return exactly that which it had received under the contract'. CECOS contended that 'sperm is an indivisible part of the body and cannot be inherited, in the absence of specific instructions from the sperm donor'. Because Alain Parpalaix left no instructions concerning his spermatozoa at the time of the deposit or when his death was imminent, CECOS refused to release the spermatozoa, saying "such therapeutic contract creates an obligation only toward a 'patient', and cannot be extended to include his wife." The French tribunal decided that human spermatozoa are not 'movable and inheritable property', and thus "declined to apply ordinary contract principles. Instead, describing spermatozoa as the 'seed of life', tied to a fundamental liberty of a human being to procreate or to avoid procreation", the court ruled that the sperm donor has a right to decide their use. The French tribunal found Parpalaix's intent 'unequivocal' (if not 'absolute'), as shown by his 'deep desire' to make his wife 'the mother of a common child', whether conception occurs during his lifetime or after his death. But, because CECOS did not inform Alain Parpalaix, in advance, of its intent not to release the spermatozoa, the French court ruled that CECOS implicitly consented to the release. On August 1, 1984, the Tribunal de Grande Instance de Creteil ordered the spermatozoa to be released saying, 'Corinne Parpalaix and her physician have the authority to decide whether to go ahead with the actual insemination'. CECOS did not appeal. Corinne Parpalaix was inseminated in November 1984, but did not become pregnant.

\section{United Kingdom \\ Diane Blood, 1997}

Mr Blood was diagnosed with meningitis and died within 4 days. When he was comatose prior to death, physicians removed two samples of spermatozoa at Mrs Blood's request. In a conversation with his wife before the illness, Mr Blood reportedly had approved of the idea of posthumous use of his spermatozoa to inseminate her (Blyth and Cameron, 1998; Blood, 1998). After the sperm removal, the Human Fertilisation and Embryology Authority refused Mrs Blood permission to be inseminated because the spermatozoa had been stored unlawfully, based on the Human Fertilisation and Embryology Act's requirement of the man's explicit prior consent for sperm storage.

\section{CONCLUSION}

As the above cases indicate, the subject of posthumous reproduction bears considerable social and medicolegal implications. The medical fraternity has to work within the boundaries of the law of the land. There is need for policy statements on this issue by authorities regulating ART procedures. The medical fraternity has to ensure that valid consent of the deceased is available. The doctors involved have a right to refuse, if they are not comfortable with the request. Prior to embarking on ART procedures, adequate mourning time of at least one year should have elapsed for the surviving partner. We should not lose focus of the welfare of the unborn child at any time. These children need to be followed up long-term, to study their psychosocial wellbeing. This will be the basis for future policies and law on this subject.

\section{REFERENCES}

1. R Edwards, et al. Destruction of Cryopreserved Embryos, Human Reproduction 1997;12:3.

2. Evelyne Aziza-Shuster. Human Reproduction 1994;9(11):218285.

3. Rothman CM. A method for obtaining viable sperm in the post mortem state. Fertil Steril 1980;34:512.

4. Ohl, et al. Procreation after death or mental incompetence: Medical advance or technology gone awry? Fertil Steril 1996;66: 889-95.

5. Nolan K, Rothman CM, Ross JW. Live sperm, dead bodies. Hastings Cent Rep 1990;20:33-34.

6. Pozda R. Sperm collection in the brain-dead patient. Dimensions Crit Care Nursing 1996;15:98-99. 
7. Townsend MF III, Richard JR, Witt MA. Artificially stimulated ejaculation in the brain-dead patient: A case report. Urology 1996;47:760-62.

8. Iserson KV. Sperm donation from a comatose, dying man. CambQ Healthcare Ethics, 1998;7:209-17.

9. Kerr SM, Caplan A, Polin G, et al. Postmortem sperm procurement. J Urol 1997;157:2154-58.

10. Allen JE. Woman Pregnant by Sperm from Corpse. Associated Press July 1998b;16.

11. Lota L. Baby Born from Dead Father’s Sperm. Associated Press March 1999;26.

12. Kristine S Knaplund. Postmortem Conception and a Father's Last Will, 46 Ariz L Rev 2004;91.

13. DePaul J. Health Care L 1999;39.

14. Jessica Weiner, Lori Andrews. The Donor Egg: Emerging Issues in Liability and Paternity, 25 Fam. Advoc. 15 (Fall 2002).

15. Susan L Crockin, Nanette Elster. Cryopreserved Embryos: Understanding and Making Choices, 18 Amer J Fam L (1998b).

16. Ralph C Brashier. Children and Inheritance in the Nontraditional Family, 1996 Utah L Rev 1996;93:158-90.

17. Oklahoma has a statute expressly protecting egg donors; 10 Okla. Stat $§ 555$ (2004).

18. Restatement (Third) of the Law of Property. § 2.1, Comment (1999).

19. Brianne M Star, A Matter of Life and Death: Posthumous Conception, 64 La L Rev 613 (Spring 2004).

20. Uniform Parentage Act (2000, as amended 2002), § 707, 9B ULA.

21. Susan L Crockin et al. Adoption and Reproductive Technology Law in Massachusetts 10.2.4, 2000.

22. Bahadur G. Posthumous assisted reproduction (PAR) Cancer patients, potential cases, counseling and consent. Hum Reprod 1996;11:2573-75.

23. Webb SM. Raising sperm from the dead. J Androl 1996;17: 325-26.

24. Benshushan A, Schenker JG. The right to an heir in the era of assisted reproduction. Hum Reprod 1998;13:1407-10.
25. Aziza-Shuster E. A child at all costs: Posthumous reproduction and the meaning of parenthood. Hum Reprod 1994;9:2182-85.

26. Lansac J. French law concerning medically-assisted reproduction. Hum Reprod 1996;11:1843-47.

27. Brahams, D. Widow appeals over denial of right to husband's sperm. Lancet 1996;348:1164.

28. Brahams D. A unique case of frozen sperm export. Lancet 1997;349:448.

29. Smith, GP III. Australia’s frozen ‘orphan’ embryos: A medical, legal, and ethical dilemma. J. Family Law 1985-86;24:27-41.

30. ICMR/NAMS Guidelines, http://www.icmr.nic.in/art/ Chapter_3.pdf.

31. Carson Strong, et al. "Ethics of postmortem sperm retrieval" Human Reproduction 2000;15(4):739-45.

32. Frances R Batzer, Joshua M Hurwitz, Arthur Caplan. Postmortem parenthood and the need of a protocol with posthumous sperm procurement. Fertil Steril 2003;79(6).

33. Pennings G, G de Wert, Shenfield F, Cohen J, Devroey P, Tarlatzis B. ESHRE Task force on Ethics and Law 11: Posthumous Reproduction. Human Reproduction 2006;21(12): 3050-53.

34. Orr RD, Siegler M. Is posthumous semen retrieval ethically permissible? J Med Ethics 2002;28:299-303.

\section{SUGGESTED READING}

\section{Legislation}

1. HFEA 1990

2. Schedule 2

3. Schedule 3

4. UPA

5. Dutch Civil Code

\section{Books}

Assisted Reproductive Technology: A Guide to the Emerging Law and Science, March 2006 Charles P Kindregan, Jr and Maureen McBrien. 